\title{
Retrospective assessment of specific effects of exposure of workers to PCBs in Slovakia
}

\author{
Tatiana Kimáková1,A-F, Zuzana Nevolná2, ${ }^{2-F}$, Janka Vašková ${ }^{3, E-F}$, Vladimír Bencko ${ }^{4, A, C-F}$ \\ ${ }^{1}$ Faculty of Medicine, Department of Public Health and Hygiene, Pavol Jozef Šafárik University, Košice, Slovakia \\ ${ }^{2}$ St. Elizabeth University of Health and Social Science, Bratislava, Slovakia \\ ${ }^{3}$ Faculty of Medicine, Department of Medical and Clinical Biochemistry and LABMED, Pavol Jozef Šafárik University, \\ Košice, Slovakia \\ ${ }^{4}$ 1st Faculty of Medicine, Institute of Hygiene and Epidemiology, Charles University, Prague, Czech Republic \\ A - Research concept and design, B - Collection and/or assembly of data, C - Data analysis and interpretation, \\ $D$ - Writing the article, E-Critical revision of the article, F-Final approval of article
}

Kimáková T, Nevolná Z, Vašková J, Bencko V. Retrospective assessment of specific effects of exposure of workers to PCBs in Slovakia. Ann Agric Environ Med. 2018; 25(3): 421-427. doi: 10.26444/aaem/86307

\begin{abstract}
Introduction and objective. Polychlorinated biphenyls (PCBs) have been used commercially since 1929 as dielectric and insulating non-flammable substances, additives for paints, etc. In Slovakia, 60 chemical production workers highly exposed to PCBs (mainly to Delor 103) were studied with duration of exposure ranging from 3 months to 19 years.

Materials and method. Clinical examinations of skin, skin histology and laboratory tests concerning lipid metabolism, iron metabolism and levels of copper provided comparisons with a control group of healthy individuals and/or the upper limits of normal values.

Results. Skin changes were found in $47 \%$ of individuals. In most cases, milia-like efflorescences (57.14 \%) occurred, as well as comedones (55.35\%); other symptoms occurred in a smaller number of workers. Hyperkeratosis, acanthosis of the epidermis (particularly in hair follicles), and a cellular infiltration of the corium were all found through histology. The intensity of cutaneous affections was associated with the changes in laboratory tests. Elevated triglycerides, cholesterol, and phospholipids were found in exposed workers. After a further two years, a significant increase in triglycerides was found in exposed individuals when compared with the control group. In addition, a significant increase in serum levels of copper, and total and unsaturated iron-binding capacity was detected.

Conclusions. Anamnesis showed that some people directly exposed to PCBs may develop skin changes after three months of occupational exposure. The results represent a unique snapshot of worker exposure at a given location, representing the basis for comparison with the population who grew up in the area and still live there today.
\end{abstract}

\section{Key words}

iron metabolism, lipid metabolism, PCBs, serum copper, skin lesions

\section{INTRODUCTION}

Polychlorinated biphenyls (PCBs) have been used commercially since 1929 as dielectric and insulating nonflammable substances (mixtures in capacitors, transformers, hydraulic fluids), additives for paints, plastics, etc. The most common brand names of commercial products are Aroclor, Clophen, Phenoclor, Kanechlor, Pyralene, Fenclor and Delor [1], the production of which is currently prohibited in many countries. In order to meet technical requirements, the commercial product must reach a certain degree of chlorination, usually in the range of $21-68 \%$. Based on the structural characteristics, the number of chlorine atoms can distinguish between 209 congeners. Based on structural and toxicological similarity with dioxin, PCB compounds can be divided into dioxin-like and non dioxin-like compounds. The first type are agonists of the arylhydrocarbon hydroxylase receptor $(A h R)$, and the others effects are mediated through enhancing the ryanodine receptors activity (RyR) [2-5].

While PCBs can enter the body through the skin and respiratory system, most current exposure is through the

Address for correspondence: Tatiana Kimáková, Pavol Jozef Šafárik University in Košice, Faculty of Medicine, Department of Public Health and Hygiene, Šrobárova 2, 04180 Košice, Slovak Republic

e-mail: tatiana.kimakova@upjs.sk

Received: 08.02.2018; accepted: 06.03.2018; first published: 09.04.2018 food chain. As fat-soluble compounds, they bioaccumulate in the adipose tissues of animals and humans. PCB exposure rate is then reflected in their concentration in the blood, breast milk, adipose tissue, and umbilical cord blood, placenta, or hair. The negative effects on the body include enzymatic disorders, and biochemical changes with subsequent morphological effects. High exposure and long term intoxication can cause death. High concentrations are associated with serious skin disease (e.g. acne chlorina), changes in skin and nail pigmentation, eye irritation, and hepatic impairment (fatty liver). PCBs cause respiratory irritation, immune system disorders, headaches, dizziness, reduction in the concentration of dopamine in the midbrain, depression, memory loss, anxiety, fatigue, impotence, and other additional difficulties. The presence of PCBs in the body decreases concentrations of T3 and T4 and, during in utero development, lowers birth weight and causes changes in postnatal development. In humans, it is believed to increase the risk of breast cancer, endocrine and reproductive disorders [6, 7].

In the Michalovce district of eastern Slovakia, Chemko was produced for 25 years (1959-1984) with an annual production of about 21,500 tons of a commercial mixtures of PCB (Delor 103, 104, 105, 106, Delotherm DK and DH, Hydelor 137). The congener patterns of Delors 103, 104, 105, and 106 resembled Aroclors 1242, 1248, 1254, and 1260 
[8]. Approximately 11,613 tons of the total production was utilized within former Czechoslovakia and the remainder were exports. Simultaneously, an estimated 1,600 tons of waste PCB was produced (especially residues of which contain highly chlorinated biphenyls, terphenyls and polychlorinated dibenzofurans). Most of the waste was stored, if not completely destroyed. However, due to its improper disposal during early production, the Laborec river and dam at Zemplínska Sírava suffer long-term contamination of the environment [9].

A relationship exists between age and the accumulation of PCBs in the blood lipids which may be partly due to higher PCB exposure of the former population in the 1970s. Consistent with this, particularly high levels of dioxin-like compounds were found in residents from the Michalovce district, and in children [10], with the highest concentrations around the age of 60 [9]. Over the last 20 years, however, a decrease in PCB blood concentrations was measured within the other European Union countries. In areas with severe contamination, concentrations have not decreased, even in the last 10 years [11].

Human milk monitoring programmes have also been implemented in many countries, including the Czech Republic, to assess the current exposure levels. The first data on sum PCBs in Czech human milk samples have been published in local journals since 1985 and reviewed in [12]. Some other studies concerning PCBs were performed in the last decade to know more about the local differences in the exposure and body burden $[2,13]$. In [14], the authors found exposure of breast-fed infants to PCBs in the Czech Republic to be close to the upper limit of the European range. To test that exposure to PCBs causes deterioration of the outer hair cells of the cochlea, the researchers in [15] measured serum PCB concentrations in 12-year-old children residing in three districts in the Slovak Republic by using high-resolution gas chromatography with microelectron capture detection. In other studies, an association between PCB exposure and deficits in cochlear function in young children exposed to environmental PCBs has been also confirmed $[5,15,16]$.

\section{OBJECTIVE}

Given the consistent interest in the presence of higher concentrations of PCBs in contaminated areas, the aim of this study was to describe specific findings on the skin, and parameters reflecting liver impairment (e.g. parameters reflecting metabolism of copper and iron) in workers exposed to PCB for up to 19 years during production, which are significant for identifying possible effects of exposure and clarifying a possible health consequences as a result of exposure to a persistent environmental burden.

\section{MATERIALS AND METHOD}

A total of 60 chemical production workers, of whom 50 were men and 10 women and aged 19-60 years, underwent histological and biochemical analysis to assess the effects of PCB exposure within the mandatory health checks. This was the total number of employees directly involved in PCB production (using instrumentation equipment, and women as cleaners and technicians), therefore directly exposed to PCBs (as well as benzenes, biphenyls, polyphenyls, carbon disulphide, and other additives) through the skin, in particular uncovered parts of the body, by inhalation and ingestion. The shortest duration of exposure was three months with the longest being 19 years.

At the time of testing and sampling, low-chlorinated biphenyl, Delor 103 was the most highly produced. From the beginning of industrial production in 1959 - 1966, only Delor 106 was produced. Production of Delor 103 began in 1967; subsequently, Delor 105 in 1968, and Hydelor and Delotherm since 1969 were produced. Of the total PCB produced in former Czechoslovakia in 1974, products with a chlorine content exceeding $48 \%$ of wt. represented up to $32.5 \%$. The portion of higher chlorinated derivatives was $17 \%$ in 1975 , and in 1976 fell below $15 \%$ of total production. Delors 103, 104, 105 and 106 resembled Aroclors 1242, 1248, 1254 and 1260. Delors contained chloronaphthalenes and chlorinated dibenzofurans as impurities at concentrations $\mathrm{mg} / \mathrm{g}$ - greater than those found in the corresponding Aroclors [9]. Values of PCBs concentration in the air were not determined.

The handling and storage of data took place only from samples for which consent was obtained between 1975 1977 , which is also the reason for reporting a lower number of workers within biochemical analyzes (34 exposed men; average age 39 years). Study enrollment included 22 individuals who were not Chemko employees (reported as an unexposed or control group) of average age 35.6 years. The clinical examinations were repeated two years later on the same individuals from the said groups of workers and the control.

Routine biochemical tests were conducted within the medical examination concerning lipid parameters, iron metabolism and assessment of copper levels. The fasting levels of triglycerides (TAG) by the enzymatic method according to [17], total cholesterol according to [18], phospholipids by the method described by [19], and unsaturated ironbinding capacity, copper, and iron content by means of BioLa-Tests (Lachema Brno, Czech Republic) were determined in serum. In individuals with visible skin pathologies, skin prick biopsies from the cheek and retroauricular areas were provided. The biopsy samples were fixed in $10 \%$ formalin buffered to neutral $\mathrm{pH}$, subjected to routine histological processing and stained with hematoxylin-eosin [20].

The results were compared with physiological reference range values validated for the population when routinely introduced methodologies in a hospital biochemical laboratory. The obtained values were analysed using an unpaired t-test.

\section{RESULTS}

56 workers were dermatologically examined for skin lesions. The average age of those affected was 35 years and the average duration of exposure was 24 month (Tab. 1). Pathological findings in the skin consisted of visible, raised, densely spread comedones, papular milia-like efflorescences and sporadically occurring cysts (Fig. 1). The extent and localisation of pathological findings on the skin is shown in Table 1. The most difficult cases involved cysts, especially around the ears, sometimes on the chest. The disease began with comedones, later milia-like efflorescences emerged, followed by papular efflorescences, and the eventual formation of cysts. In a few cases, temporary manifestations of dermatitis and 
Table 1. Worker characteristics examined for pathological findings on the skin, and their location

\begin{tabular}{|c|c|c|}
\hline Characteristic & $\mathrm{N}$ & Occurence (\%) \\
\hline $\mathrm{N}$ & 56 & \\
\hline age [yrs.] ( \pm SD) & $35 \pm 10$ & \\
\hline age [yrs.] (med, min-max) & $33(19-56)$ & \\
\hline exposure time [month] (med, min-max) & $24(3-228)$ & \\
\hline \multicolumn{3}{|l|}{ Particular skin changes } \\
\hline Milia-like efflorescences & 32 & 57.14 \\
\hline Comedones & 31 & 55.35 \\
\hline Comedones and milia-like efflorescences & 13 & 23.21 \\
\hline Papular efflorescences & 13 & 23.21 \\
\hline Skin hyperpigmentation & 12 & 21.42 \\
\hline Eczematous skin manifestations & 7 & 12.50. \\
\hline Hordeloum & 1 & 1.78 \\
\hline Folliculitis & 1 & 1.78 \\
\hline Subcutaneous nodules & 1 & 1.78 \\
\hline \multicolumn{3}{|l|}{ Localization } \\
\hline Face & 49 & 87.50 \\
\hline Cheek & 27 & 48.21 \\
\hline Auricles & 7 & 12.50 \\
\hline Hands & 14 & 25.00 \\
\hline Chest & 10 & 17.78 \\
\hline
\end{tabular}

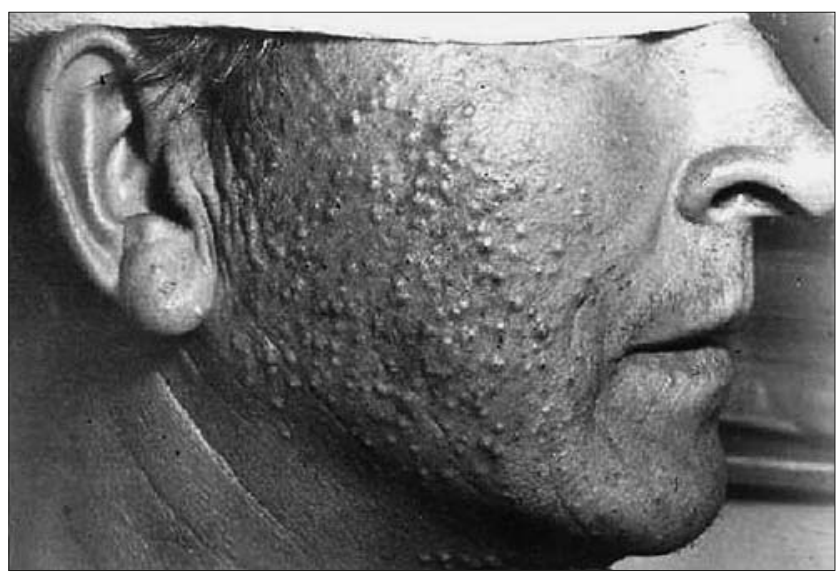

Figure 1. A 43-year-old man after 15 years' exposure to PCBs in their manufacture. Comedones can be seen on the cheeks, a number of papular efflorescences and densely spread milia-like efflorescences

eczematous occurred. The focal area of pathological changes was the face, particularly around the cheekbones, ears, arms, chest and back. The nose, lips and chin remained mostly unaffected. Chronic conjunctivitis and watery eyes were common (45.88\% and $31.17 \%)$. In most cases, milia-like efflorescences occurred (57.14\%) and comedones (55.35\%), other symptoms occurred in smaller numbers. When exposed to PCBs, milia-like efflorescences and comedones appeared first, after as little as three months exposure.

The predominant finding of histological preparations was the presence of enlarged follicles and pathologically reduced sebaceous glands (Fig. 2-4). The histological changes of skin showed hyperkeratosis, keratotic plugs in the follicles, acanthosis of the epidermis and the hair follicle, and cellular infiltration of the corium.
Table 2. Worker characteristics examined for biochemical findings

\begin{tabular}{lcc}
\hline Characteristic & $\mathrm{N}$ & Occurence (\%) \\
\hline $\mathrm{N}$ & 34 & \\
\hline age [yrs.] ( $\pm \mathrm{SD})$ & $39 \pm 11$ & \\
\hline age [yrs.] (med, min-max) & $41(19-60)$ & \\
\hline exposure time [month] (med, min-max) & $48(4-192)$ & 47 \\
\hline with skin lesions & 16 & 53 \\
\hline with elevated TAG & 18 & 21 \\
\hline with elevated cholesterol & 7 & 35 \\
\hline with increased phospholipids & 12 &
\end{tabular}

Table 3. Comparison of serum lipid levels in workers $(N=34)$ and unexposed $(\mathrm{N}=22)$ individuals within 2 years

\begin{tabular}{lcccc}
\hline & $\begin{array}{c}\text { Timing of } \\
\text { determination }\end{array}$ & $\begin{array}{c}\text { Unexposed } \\
(\mathrm{mmol} / / \mathrm{l})\end{array}$ & $\begin{array}{c}\text { Workers } \\
(\mathrm{mmol} / / \mathrm{l})\end{array}$ & $\begin{array}{c}p \\
\text { (within 2 yrs) }\end{array}$ \\
\hline TAG & 2 yrs later & $1.17 \pm 0.14$ & $2.57 \pm 0.33^{* * *}$ & $* * * 12$ \\
\hline Cholesterol & & $5.15 \pm 0.15$ & $5.85 \pm 0.18^{* *}$ & \\
\hline & 2 yrs later & $5.10 \pm 0.15$ & $6.02 \pm 0.54^{* * *}$ & \\
\hline Phospholipids & & $2.86 \pm 0.08$ & $3.11 \pm 0.09^{*}$ & \\
\hline & 2 yrs later & $2.89 \pm 0.09$ & $3.01 \pm 0.28$ & \\
\hline
\end{tabular}

Statistical significance at ${ }^{*} p<0.05 ;{ }^{* *} p<0.01,{ }^{* * *} p<0.001$

Table 4. Total iron-binding capacity (TIBC), unsaturated iron-binding capacity (UIBC), serum iron (Fe) and copper (Cu) in workers

\begin{tabular}{lcccc}
\hline & $\begin{array}{c}\text { TIBC } \\
(\mu \mathrm{mol} / \mathrm{l})\end{array}$ & $\begin{array}{c}\text { UIBC } \\
(\mu \mathrm{mol} / \mathrm{l})\end{array}$ & $\begin{array}{c}\mathrm{Fe} \\
(\mu \mathrm{mol} / \mathrm{l})\end{array}$ & $\begin{array}{c}\mathrm{Cu} \\
(\mu \mathrm{mol} / \mathrm{l})\end{array}$ \\
\hline exposed individuals & $123.05 \pm 28.27$ & $94.05 \pm 24.46$ & $27.43 \pm 10.29$ & $29.36 \pm 6.36$ \\
\hline reference range & $44.80-71.68$ & $30.47-45.70$ & $14.33-25.98$ & $13.37-24.30$ \\
\hline$p$ & $* *$ & $* *$ & - & $* *$ \\
\hline$\%$ increase & 100 & 100 & 42.85 & 81.25 \\
\hline
\end{tabular}

Statistical significance at ${ }^{* *} p<0.01$

Biochemical analyses of TAG, total cholesterol, and phospholipids were carried out on 34 occupationally exposed workers, the results of which are summarized in Table 2. There is no dependency between the changes in serum TAG, cholesterol, phospholipids, and skin. Skin changes were found in $47 \%$ of workers, elevated triglyceride levels in $53 \%$, increased cholesterol content in $21 \%$ and increased levels of phospholipids in $35 \%$ of workers exposed to PCBs (Tab. 2). (Values of unexposed individuals were within the reference range for the given parameters.) After two years, TAG concentrations were shown to have significantly increased in the group of workers $(2.17 \pm 0.20$ and two years later 2.57 \pm 0.33 ). In the first sampling, and two years later, significant differences were observed between workers and unexposed individuals in TAG, total cholesterol and phospholipid levels (Tab. 3). The parameters of lipid metabolism were increased in workers exposed to PCBs.

Other biochemical parameters were measured in the second screening to take into account metabolism of iron and copper levels, as this is required in the regulation of iron metabolism. A significant $(p<0.01)$ increase was found in copper levels, and in both the total iron binding capacity and free (unsaturated) iron binding capacity. Iron levels, however, remained without significant changes (Tab. 4). 


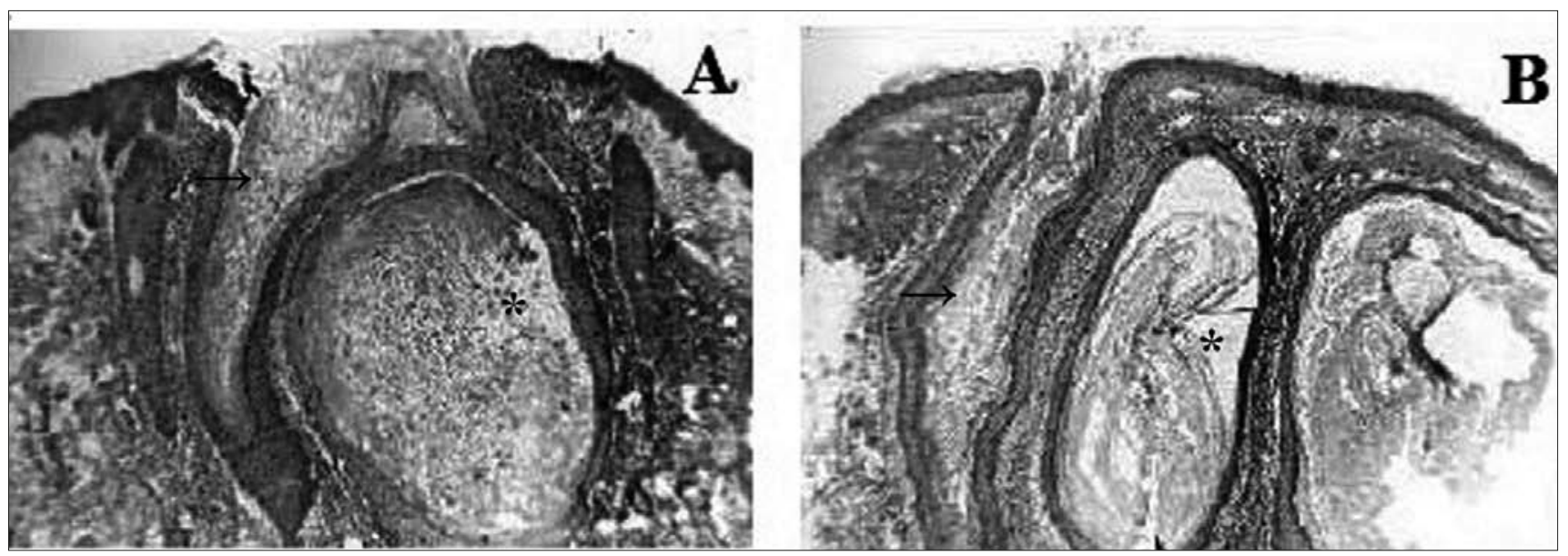

Figure 2. A - the skin of the right cheek of a 55-year-old man after 3 years' exposure to PCBs. B - extensive comedones with necrosis of the epidermis at the edges, and spheric cellulisation in the corium (magnification 52x)

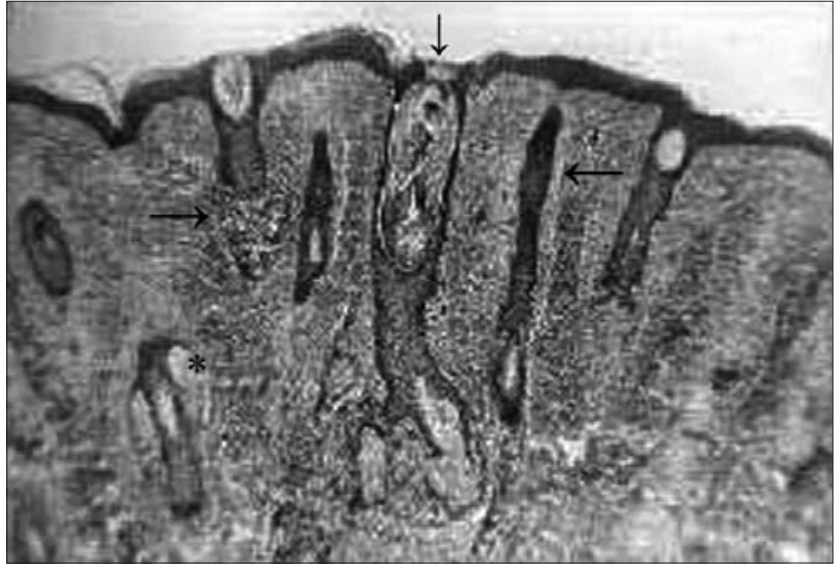

Figure 3. The skin of the left retroauricular area of a 42-year-old man after 14 years' exposure to PCBs. Hyperkeratosis in the follicle opening in the middle, with the formation of comedones, loss and disappearance of the sebaceous glands, disappearance of sweat glands, and spheric cellulisation in the corium, with the maximum around hair follicles (magnification 52x)

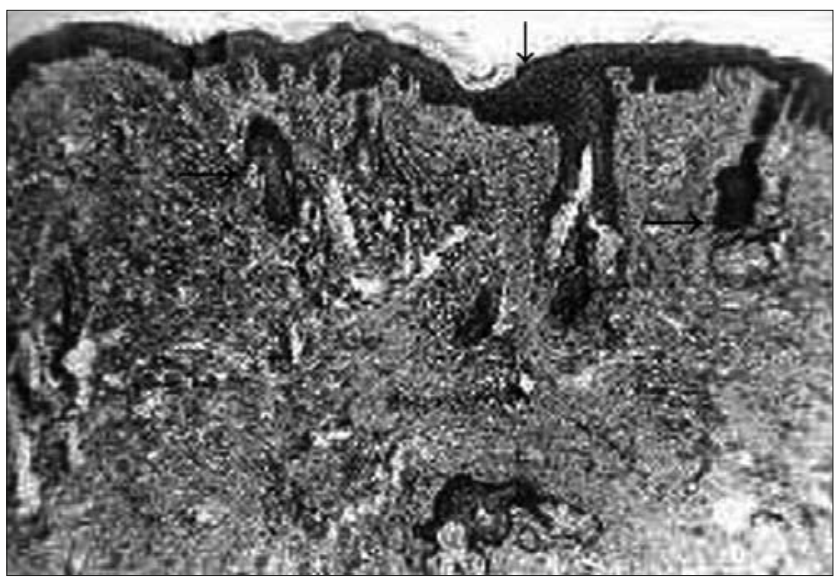

Figure 4. The skin of the left retroauricular area of a 42-year-old man after 14 years' exposure to PCBs. Mild surface hyperkeratosis and signs of acanthotic extension of epidermis, noticeable decline to disappearance of the sebaceous glands, absence of sweat glands, and perifollicular spheric cellulisation (magnification 52x)

\section{DISCUSSION}

Recognising the symptoms of PCB exposure for workers exposed during the manufacturing process often identified signs of skin damage. Skin mostly responds uniformly to various chlorinated hydrocarbons; the changes only differ in intensity for a given individual. The extensive damage to skin in selected workers, such as numerous cysts and boils, was not found as they underwent preventive medical checks at the initial stage of skin disease. In selected workers, evidence was found of comedones, milia-like lesions and small cystic lesions on the face and in the cheekbone (Fig. 1). In one case, cystic lesions appeared in the retroauricular area after 14 years of PCB exposure in a 42 -year-old man. These did not disappear even after a three-year break without PCB contact. Surgical intervention was therefore required for their removal by total extirpation. Similarly, cases of chlornacne, folliculitis, or dermatitis were observed by Maroni et al. due to primary irritative allergic sensitising agents in the examination of electric capacitor manufacture by workers for many years [21]. Other observed changes in the skin also included erythema, dryness, and hyperpigmentation. Redness of the conjunctiva, palpebral hyperpigmentation, oedema, abnormal secretions from the eyes, and enlargement of the Meibomian glands were also observed [22].

However, in the study of [23] no definite case of chloracne was identified, while a number of mild and/or transient irritant symptoms (e.g. eye irritation, chest pain on walking, wheezing) were clearly confirmed in exposed workers. It seems that other dermal effects, such as temporary inflammation or oedema of the skin and chloracne, appear to be related to the incidence and magnitude of the individual's dermal contact with PCB fluids or from high exposure to heated PCB vapours, suggesting PCBs and/or PCDFs (polychlorinated dibenzofurans) as the causative agents [24].

Usually, chloracne appears in individuals with serum PCB levels 10-20 times higher than those of the general population. However, there is great variability among individuals and there may also have been exposure to relatively high levels of PCDFs [24, 25]. Found dioxin-like substances and PCDFs as relatively potent chloracnegens. In doing so, the action of the PCBs on the skin, as well as their other toxic effects depends on the structure and number of chlorine atoms in the compounds. An obvious prevalence of abnormal dermatological symptoms during or after exposure to PCBs is summarized by Lindell [11]. Histological changes in the skin showed hyperkeratosis, keratotic plugs in the follicles, acanthosis of the epidermis and hair follicle, and 
cellular infiltration of the corium. Expansion and elevation of follicular orifice was also recorded. One possible explanation for these changes, proposed by [26] is based on stem-cell theory, which makes sense as PCB substances are potent ligands for AhR. B lymphocyte maturation protein 1 (Blimp1), a negative regulator of $\mathrm{c}-\mathrm{Myc}$, is a AhR regulated gene in epidermal keratinocytes and sebocytes. Both, c-Myc and Blimp1 are supposed to play an important role in 2,3,7,8-tetrachlorodibenzo-p-dioxin (TCDD)-induced skin pathology. An activation of c-Myc favours differentiation along the lineages of the interfollicular epidermis and sebaceous glands, and results in the appearance of groups of differentiated sebocytes within the interfollicular epidermis. Inactivation of $\mathrm{c}-\mathrm{Myc}$ results in hypoplasia of the sebaceous glands. Loss of Blimp1 results in the elevation of c-Myc expression and hyperplasia of the sebaceous glands [27]. Taken together, the TCCD/AhR/ARNT/Blimp1 and CYP1A1/ c-Myc pathways may very likely be the proposed signalling pathways of TCDD on skin stem-cell progenitors, leading to TCDD-induced abnormal differentiation of sebaceous glands. Some PCBs (i.e. PCB 77, PCB 126 and other dioxinlike congeners) are referred to as agonists of $\mathrm{AhR}$, mediating the expression and epigenetic regulation of enzymes involved in xenobiotic metabolism $[28,29]$.

The histological findings in the presented study are similar to those previously mentioned, it may therefore be supposed that the changes in skin exposed PCB are of the same character. As it is visible and more easily traceable, it is clear that the clinical picture of skin lesions, the intensity and dynamics of their development, depends on the concentration of PCBs in the air, the structure and number of chlorine atoms in PCB congeners, moisture, temperature, individual sensitivity and metabolism of PCBs. Tsai et al. [30] discovered that genetic polymorphisms in CYP1A1 (cytochrome P450 1A1 gene) and glutathione-S-transferase (GST) are related to PCB-induced skin manifestation susceptibility.

Changes to the enzymes involved in phase I and II detoxification of xenobiotics cause substantial interference with the metabolism of other tissues noting metabolic sideeffects of PCBs. This also provides a further explanation of the results of biochemical blood tests.

The study by Rocha de Oliveira et al. demonstrated liver injury following PCB administration to rats [31]. Biochemical parameters reflecting these adverse effects in serum of workers were also measured. The current results showed that, in a randomly-selected group of workers exposed to the PCBs over a year, increased serum lipids, particularly triglycerides, and partly total cholesterol were increased (Tab. 3,4). After prolonged exposure, more workers showed increased triglyceride levels by an average of up to $200 \mathrm{mg} / 100$ $\mathrm{ml}$, with elevations occurring in $72 \%$ of exposed persons. Elevated triglycerides have not always been accompanied by the presence of significant skin changes. The presented results of high levels of TAG and other lipid parameters reported here are consistent with conclusions made in the study by [32], where elevated serum concentrations of lipids were significantly associated with serum concentrations of PCBs. The strongest associations were seen for PCB congeners with three or four ortho and/or at least eight substituted chlorines. Furthermore, [33] found that PCB and pesticide levels are positively correlated with serum total cholesterol and triglyceride concentrations. A possible explanation may be in the induction of Cyp1 and 2 families by PCBs [34].
This gene encodes aryl hydrocarbon hydrolase, responsible for the generation of reactive epoxide intermediates during metabolisation of aromatic compounds. These metabolites are continuously produced in substantial quantities following tissue attack by reactive oxygen species, which are accumulated by the presence of PCBs. The primary effect of oxidative damage is to damage or break some of the processes in the mitochondria, as demonstrated by the action of Aroclor 1254 on mouse hepatocytes. Among others, a very important finding in the current study was the significant decline in the mitochondrial aconitase activity, and $\beta$-oxidation of fatty acids [35].

Therefore, from a summary of current knowledge, it is suggested as a possible explanation for the TAG increase that the inhibition of mitochondrial aconitase by reactive oxygen species from the metabolism of PCBs, releases iron from aconitase Fe-S clusters. Free iron itself can then increase the conditions of oxidative stress. A reduction in the activity of aconitase in the citric acid cycle results in the accumulation of citrate, which is transmitted to the cytoplasm, where it activates ATP citrate lyase, acetyl-CoA carboxylase, fatty acid synthase, and substantially increases the synthesis of fatty acids.

There is, however, another serious fact related to PCB toxicity facilitated through interaction with $\mathrm{AhR}$, which is impaired gluconeogenesis. This is caused by a reduction in glucose-6-phosphatase activity and gene expression of phosphoenolpyruvate carboxykinase, including a decrease in body weight $[36,37]$. Glycerol is synthesised through triglyceride-fatty acid cycling in white adipose tissue, skeletal muscle and liver, predominantly through glyceroneogenesis. Surprisingly, the highest rate of glyceroneogenesis in adipose tissue is observed when fatty acid synthesis and triglyceride deposition is high [38]. Unless the actions of PCBs inhibit the release of glucose from the liver (inhibition of glucose6-phosphatase) for glycolysis, glucose-6-phosphate can be utilized in the pentose phosphate pathway, thus contributing to the formation of NADPH. Due to the increase in acetyl$\mathrm{CoA}$ in the cytosol (a requirement of synthesis), along with the abundance of NADPH, the liver creates ideal conditions for the synthesis of cholesterol. The overall expected effects on the liver could be increase synthesis of cholesterol, lipid particles, as also demonstrated in the presented study, and tissue injury. The presented results of high levels of TAG and other lipid parameters are consistent with conclusions made in the study by [32], where elevated serum concentrations of lipids were significantly associated with serum concentrations of PCBs.

However, liver is the centre of iron metabolism control, and site of hormone regulating iron uptake, distribution and storage [39]. Determination of iron metabolism parameters is therefore of undeniable importance in monitoring the toxic effects of PCBs, particularly with a view to the prevention of oxidative damage to tissues. In evaluating total iron-binding (transferrin) capacity (TIBC) and unsaturated iron-binding capacity (unsaturated transferin, UIBC), values were found to have more than doubled in all workers when compared to the reference range (Tab. 4). In [40], the authors also found significantly increased serum levels of TIBC and UIBC in rats treated with Aroclor 1254. This phenomenon can be explained by transferrin overproduction. However, transferrin expression is enhanced by hypoxia-inducible factor-1, whose $\beta$ subunit is identical to the aryl hydrocarbon receptor nuclear 
Table 5. Approximate exposures estimates based on TCDD level in plasma (in $\mathrm{pg} / \mathrm{g}$ fat) in selected groups of subjects with the heaviest exposure, using a half-life of $7-10$ years $[47,48]$

\begin{tabular}{lcc}
\hline Place of exposure & Years & $\begin{array}{c}\text { TCDD level in plasma } \\
\text { (pg/g fat)* }\end{array}$ \\
\hline USA - veterans [49] & $1962-1971$ & 50 \\
\hline Vietnam - population [50] & $1962-1971$ & $120-260$ \\
\hline New Zealand [51] & late 1960s & 300 \\
\hline Seveso, Italy [52] & 1976 & 390 zone A; 78 zone B \\
\hline BASF Ludwigshafen, Germany [53] & 1953 & 400 \\
\hline Netherlands [49] & 1963 & 1,434 \\
\hline USA, 12 chemical companies [54] & $1950 s-1970 s$ & 2,000 \\
\hline Linz, Austria [55] & 1973 & 2,682 \\
\hline Spolana, Czech Republic [56-59] & $1965-1968$ & 6,100 \\
\hline Population level [60] & 2000 & 2 \\
\hline
\end{tabular}

*Maximum mean back-calculated TCDD level in plasma to the date of exposure (pg/g fat)

translocator (ARNT). This is known to heterodimerise with the AhR/dioxin receptor following ligand binding [41, 42]. The calculation of transferrin saturation tends to be lower although it is around the lower limit of the reference range. This may indicate physical strain of chronic illness. However, serum iron levels tended to be elevated (Tab. 4). [43] found that PCB-77 causes its accumulation in the liver, inhibition of hepcidin, and suppression of hepcidin expression. A study by [44] revealed that PCB153 and PCB 126 suppress hepcidin transcription through a functional oestrogen response element within the hepcidin promoter, coupled with elevated serum iron content as well as reduced hepatic and splenic iron mass. However, lowered hepcidin production in liver, macrophages and adipose tissue can cause increased intestinal absorption of iron and its release by macrophages. The reduction in hepcidin activity is therefore associated with an increased activity of the divalent metal transporter 1 , which is responsible for the absorption of iron as well as copper (as evidenced by the higher concentrations of copper in Table 4).

In a few animal studies, changes in hepatic copper and iron were found after exposure of rats to PCB 126, and copper levels were significantly increased in a dose-dependent manner [45]. Higher serum iron may also be due to the release of iron from the iron-sulphur clusters of molecules in the tissue in response to the damaging effects of oxidative metabolism of the PCBs, and actual damage to the liver tissue. In this manner, it may impair the synthesis and breakdown of haemoproteins.

In June 2005, a meeting of WHO-IPCS experts was held in Geneva during which the toxic equivalency factors (TEFs) for dioxin like compounds, including some polychlorinated biphenyls (PCBs), were re-evaluated. The concept of toxic equivalency factor was developed to facilitate risk assessment and regulatory control. Toxic equivalence factors exist for seven congeners of dioxins, 10 furans and 12 PCBs. The reference congener is the most toxic dioxin 2,3,7,8-tetrachlorodibenzo-p-dioxin (TCDD) which per definition has a toxic equivalence factor of one [46]. The environmental contaminant 2,3,7,8-tetrachlordibenzop-dioxin (TCDD) belongs to the cathegory of highly toxic, persistent organic pollutants that accumulate in animal fat and plant tissues. The main source of exposure in humans is the food chain. The half-life of TCDD in humans was estimated to be in the range of $7-10$ years (Tab. 5) $[47,48]$.

\section{CONCLUSIONS}

Anamnesis showed that some people directly exposed to PCBs may develop skin changes after three months of occupational exposure. The range of pathological changes to the skin is wide but also varies individually. Clinical investigation of possible disease manifestations in the skin can be categorized mainly to milia-like lesions, comedones, papular efflorescences, and skin hyperpigmentation. The histology of skin samples revealed hyperkeratosis and acanthosis of the epidermis, in particular in hair follicle and corium cell infiltration. In the blood serum of exposed individuals, elevated levels of total and unsaturated iron-binding capacity were observed, together with increased total copper and iron levels, and a significant increase in triglycerides.

Skin changes are visible and therefore easily identified and treated, but the impact of biochemical changes in the tissue by affecting lipid and iron metabolism are complex, long-lasting and affect the general health. The presented results are not the most recent, but are unique due to the location following PCB exposure. They are an introduction to the study of the current state of the generations in their forties who grew up and still today live near Chemko, i.e. the generation born during the period of extensive production.

\section{Acknowldgements}

The study was elaborated within research activities supported by the research programme PROGRES Q29/LF1, and partially supported by the Agency of the Ministry of Education, Science, Research and Sport of the Slovak Republic for the Structural Funds of the EU under Project RIFIV, ITMS 26110230101. The study is published in memoriam as an acknowledgement to my father Michal Šak, assoc. prof. MD. PhD. who was invited to directly address the issue of occupational dermatoses occurring in workers at the time of manufacture in Chemko Strážske.

\section{REFERENCES}

1. Johnson GW, Quensen JF, Chiarenzelli, JR, Coreen Hamilton M. Polychlorinated Biphenyls 414. In: Morrison RD, Murphy BL, editors. Environmental Forensics 416 Contaminant Specific Guide, Academic Press; 1996. p. 187-214.

2. Bencko V, Černá M, Jech L, et al. Exposure of breast-fed children in the Czech Republic to PCDDs, PCDFs, and dioxin like PCBs. Environ Toxicol Pharmacol. 2004; 18: 83-90.

3. Pessah I, Cherednichenko G, Lein P. Minding the calcium store: Ryanodine receptor activation as a convergent mechanism of PCB toxicity. Pharmacol Ther. 2010; 125: 260-285.

4. Mesnier A, Champion S, Louis L, et al. The Transcriptional effects of PCB118 and PCB153 on the liver, Adipose tissue, muscle and colon of mice: Highlighting of glut 4 and Lipin 1 as main target genes for PCB induced metabolic disorders. PloS One 2015; 10, e0128847.

5. Palkovičová Murínová L, Moleti A, Trnovec T, et al. PCB exposure and cochlear function at age 6 years. Environ Res. 2016; 151: 428-435.

6. ATSDR Case studies in environmental medicine. Polychlorinated biphenyls (PCBs) toxicity http://www.atsdr.cdc.gov/csem/pcb/docs/ pcb.pdf (access: 2018.02.01).

7. EPA. Public health implications of exposure to polychlorinated biphenyls (PCBs) https://www.epa.gov/sites/production/files/2015-01/ documents/pcb99.pdf (access: 2018.02.01).

8. Taniyasu S, Kannan K, Holoubek I, et al. Isomer-specific analysis of chlorinated biphenyls, naphthalenes and dibenzofurans in Delor: Polychlorinated biphenyl preparations from the former Czechoslovakia. Environ Pollution 2003; 126: 169-178.

9. Jursa S, Chovancová J, Petrík J, et al. Dioxin-like and non-dioxin-like PCBs in human serum of Slovak population. Chemosphere 2005; 64: 686-691. 
10. Petrik J, Drobna B, Pavuk M, et al. Serum PCBs and organochlorine pesticides in Slovakia: Age, gender, and residence as determinants of organochlorine concentrations. Chemosphere 2006; 65(3): 410-418.

11. Lindell B. The Nordic Expert Group for Criteria Documentation of Health Risks from Chemicals 146. Polychlorinated biphenyls (PCBs). Gothenburg, Sweden: University of Gothenburg, 2012.

12. Černá M, Bencko V. Polyhalogenated hydrocarbons: body burden of the Czech and Slovak populations. I. Polychlorinated biphenyls. Cent Eur J Publ Health 1999; 7: 67-71.

13. Bencko V, Skulová Z, Krečmerová M, et al. Selected polyhalogenated hydrocarbons in breast milk. Toxicol Lett. 1998; 96(97): 341-345.

14. Černá M, Bencko V, Brabec M, et al. Exposure assessment of breastfed infants in the Czech Republic to indicator PCBs and selected chlorinated pesticides: Area-related differences. Chemosphere 2010; 78(2): 160-168.

15. Trnovec T, Šovčíková E, Husták M, et al. Exposure to polychlorinated biphenyls and hearing impairment in children. Environ Toxicol Pharmacol. 2008; 25: 183-187.

16. Trnovec T, Šovčíková E, Pavlovcinová G, et al. Serum PCB concentrations and cochlear function in 12-year-old children. Environ Sci Technol. 2010; 44: 2884-2889.

17. Eggstein M, Kreutz F. A new determination of the neutral fats in blood serum and tissue. I. Principles, procedure, and discussion of the method. Klin Wochenschr. 1966; 14: 262-267.

18. Zlatkis A, Zak B, Boyle A. A new method for the direct determination of serum cholesterol. J Lab Clin Med. 1953; 41: 486-492.

19. Bartlett G. Phosphorus assay in column chromatography. J Biol Chem. 1959; 234: 466-468.

20. Luna, LG. Manual of Histologic staining methods: of the Armed Forces Institute of Pathology. Blakiston Division, McGraw-Hill, 1968.

21. Maroni M, Colombi A, Arbosti G, et al. Occupational exposure to polychlorinated biphenyls in electrical workers. II. Health effects. $\mathrm{Br}$ J Ind Med. 1981; 38: 55-60.

22. Ahlborg UG, Hanberg A, Kenne K. Risk assessment of polychlorinated biphenyls (PCBs). Copenhagen: Nordic Council of Ministers https:// kiedit.ki.se/sites/default/files/nordpcb-92.pdf (access: 2018.02.01).

23. Emmett E, Maroni M, Schmith J, Levin B, Jefferys J, et al. Studies of transformer repair workers exposed to PCBs: I. Study design, PCB concentrations, questionnaire, and clinical examination results. Am J Ind Med. 1988; 13: 415-427.

24. James R, Busch H, Tamburro C, et al. Polychlorinated biphenyl exposure and human disease. Occup Med. 1993; 35: 136-148.

25. Kimbrough R, Krouskas C. Human exposure to polychlorinated biphenyls and health effects: A critical synopsis. Toxicol Rev. 2004; 22: 217-233.

26. Ju Q, Fimmel S, Hinz N., et al. 2, 3,7, 8-Tetrachlorodibenzo-p-dioxin alters sebaceous gland cell differentiation in vitro. Exp Dermatol. 2011; 20: 320-325

27. Ikuta T, Ohba M, Zouboulis C, Fujii-Kuriyama Y, Kawajiri K, et al. B lymphocyte-induced maturation protein 1 is a novel target gene of aryl hydrocarbon receptor. J Dermatol Sci. 2010; 58: 211-216.

28. Beischlag T, Morales L, Hollingshead B, Perdew G, et al. The aryl hydrocarbon receptor complex and the control of gene expression. Crit Rev Eukaryot Gene Expr. 2008; 18: 207-250.

29. Vorrink S, Hudachek DR, Domann FE. Epigenetic determinants of CYP1A1 induction by the aryl hydrocarbon receptor agonist 3, 3",4, 4",5-pentachlorobiphenyl (PCB 126). Int J Mol Sci. 2014; 15: 1391613931.

30. Tsai P, Huang W, Lee Y, et al. Genetic polymorphisms in CYP1A1 and GSTM1 predispose humans to PCBs/PCDFs-induced skin lesions. Chemosphere 2006; 63: 1410-1418.

31. Rocha de Oliveira C, Ceolin J, Rocha de Oliveira R, et al. Effects of quercetin on polychlorinated biphenyls-induced liver injury in rats. Nutr Hosp. 2017; 29: 1141-1148.

32. Aminov Z, Haase R, Pavuk M, Carpenter DO, et al. Analysis of the effects of exposure to polychlorinated biphenyls and chlorinated pesticides on serum lipid levels in residents of Anniston, Alabama. Environ Health 2013; 12: 108.

33. Goncharov A, Haase R, Santiago-Rivera A, et al. High serum PCBs are associated with elevation of serum lipids and cardiovascular disease in a native American population. Environ Res. 2007; 106: 226-239.

34. Inui $\mathrm{H}$, Itoh $\mathrm{T}$, Yamamoto $\mathrm{K}$, et al. Mammalian cytochrome P450dependent metabolism of polychlorinated dibenzo-p-dioxins and coplanar polychlorinated biphenyls. Int J Mol Sci. 2014; 15: 14044-14057.

35. Aly H, Domènech $O$. Aroclor 1254 induced cytotoxicity and mitochondrial dysfunction in isolated rat hepatocytes. Toxicology 2009; 262: 175-183.
36. Pathak S, Kundu R. Low doses of a PCB (Aroclor 1254) affect the body weight by decreasing the activity of glucose-6-Phosphatase in the liver and kidney cells of mice. IOSR J Environ Sci Toxicol Food Technol. 2013; 3 : 16-21.

37. Zhang W, Sargis R, Volden P, et al. PCB 126 and other dioxin-like PCBs specifically suppress hepatic PEPCK expression via the aryl hydrocarbon receptor. PloS One 2012; 7: e37103.

38. Nye CK, Hanson RW, Kalhan SC. Glyceroneogenesis in the dominant pathway for triglyceride glycerol synthesis in vivo in the rat. J Biol Chem. 2008; 283: 27565-27574.

39. Drakesmith H, Prentice A. Hepcidin and the Iron-Infection Axis. Science 2012; 338: 768-772.

40. Ludewig G, Robertson L. Prostate Cancer Risk Through Exposure to Halogenated Hydrocarbons and Modulation by Dietary Supplementation. Oaidticmil http://oai.dtic.mil/oai/oai?verb=getReco rd\&metadataPrefix=html\&identifier=ADA421055 (access: 2018.02.01).

41. Rolfs A, Kvietikova I, Gassmann M, et al. Oxygen-regulated transferrin expression is mediated by hypoxia-inducible factor-1. J Biol Chem 1997; 272: 20055-20062.

42. Wenger R, Gassmann M. Oxygen(es) and the hypoxia-inducible factor-1. Biol Chem. 1997; 378: 609-616.

43. Wang L, Zhang S, Lin R, et al. PCB-77 disturbs iron homeostasis through regulating hepcidin gene expression. Gene 2013; 532: 146-151.

44. Qian Y, Zhang S, Guo W, et al. Polychlorinated biphenyls (PCBs) inhibit hepcidin expression through an estrogen-like effect associated with disordered systemic iron homeostasis. Chem Res Toxicol. 2015; 28: 629-640.

45. Lai I, Klaren W, Li M, et al. Does dietary copper supplementation enhance or diminish PCB126 toxicity in the rodent liver? Chem Res Toxicol. 2013; 26: 634-644.

46. Van den Berg M, Birnbaum LS, Denison M, et al. The 2005 World Health Organization reevaluation of human and Mammalian toxic equivalency factors for dioxins and dioxin-like compounds. Toxicol Sci. 2006; 93(2): 223-241.

47. Pelclová D, Urban P, Navrátil T, et al. Adverse health effects in humans exposed to 2,3,7,8-etrachlorodibenzo-p-dioxin (TCDD). Rev Environ Health 2006; 21: 119-138.

48. Bencko V, Foong, FYL. The history, toxicity and adverse human health and environmental effects related to the use of agent orange. In: Simeonov LI, Macaev FZ, Simeonova BG, editors. Environmental security assessment and management of obsolete pesticides in southeast Europe. Springer, Varna; 2013. p. 119-130.

49. IARC (International Agency for Research on Cancer). Polychlorinated Dibenzo-para-dioxins. Polychlorinated Dibenzo-para-dioxins and Polychlorinated Dibenzofurans. Lyon, France: IARC Monographs 1997; 69: 33-343.

50. Dai LC. Agent Orange in the Viet Nam war: History and Consequences. Hanoi, Vietnam: Vietnam Red Cross Society 2000; 1-202.

51. Smith AH, et al. Serum 2,3,7,8-tetrachlorodibenzo-p-dioxin levels of New Zealand pesticide applicators and their implication for cancer hypotheses. J Natl Cancer Inst. 1991; 84: 104-108.

52. Landi MT, Consonni D. 2,3,7,8-Tetrachlorodibenzo-p-dioxin plasma levels in Seveso 20 years after the accident. Environ Health Perspect 1998; 106: 273-277.

53. Flesch-Janys D, Becher $\mathrm{H}$, et al. Elimination of polychlorinated dibenzop-dioxins and dibenzofurans in occupationally exposed persons. J Toxicol Environ Health 1996; 47: 363-78.

54. Fingerhut MA, Halperin WE, et al. Cancer mortality in workers exposed to 2,3,7,8-tetrachlorodibenzo-p-dioxin. N Engl J Med. 1991; 324: 212-218.

55. Neuberger M, et al. Blood levels of 2,3,7,8-tetrachlorodibenzo-p-dioxin in chemical workers after chloracne and in comparison groups. Int Arch Occup Environ Health 1991; 63: 325-327.

56. Zemek A, Kočan A. 2,3,7,8-tetrachlorodibenzo-p-dioxin in soil samples from a trichlorophenol-producing plant. Chemosphere 1991; 23: 1769-1776.

57. Pazderová-Vejlupková J, Lukáš E, et al. Chronic poisoning by 2,3,7,8-tetrachlorodibenzo-p-dioxin. Pracov Lék 1980; 32: 204-209. (In Czech, English abstract)

58. Pazderová-Vejlupková $\mathrm{J}$, et al. The development and prognosis of chronic intoxication by 2,3,7,8-tetrachlorodibenzo-p-dioxin in men. Arch Environ Health 1981; 36: 5-11.

59. Pelclová D, Fenclová Z, et al. Biochemical, neuropsychological, and neurological abnormalities following 2,3,7,8-tetrachlorodibenzo-pdioxin (TCDD) exposure. Arch Environ Health. 2001; 56: 493-500.

60. Aylward LL, Hays SM. Temporal trends in human TCDD body burden: decreases over three decades and implications for exposure levels. JEAEE 2002; 12: 319-328. 